http://periodicos.uefs.br/index.php/acordasletras/index http://dx.doi.org/10.13102/cl.v20i2.4825

\title{
Retextualização, correção textual e trabalho docente: alguns apontamentos
}

\author{
Retextualization, textual correction and teaching work: some notes
}

\author{
Cícero da Silva* \\ Universidade Federal do Tocantins \\ Tocantinópolis, Tocantins, Brasil
}

\begin{abstract}
Resumo: Neste artigo, objetiva-se discutir processos de retextualização, correção textual e trabalho docente envolvendo a produção escrita na escola. A abordagem do objeto de investigação parte de uma perspectiva de análise interpretativista, sendo a pesquisa de natureza bibliográfica, fundamentada nos estudos dos gêneros do discurso na perspectiva bakhtiniana (BAKHTIN, 2006), com ênfase na retextualização (DELL'ISOLA, 2007; MARCUSCHI, 2007; SILVA; ANDRADE; MOREIRA, 2015), nas tipologias de correção e no trabalho docente envolvendo a produção textual (SERAFINI, 1995; FIAD, 2009; GONÇALVES, 2009; RUIZ, 2010; GASPAROTTO; MENEGASSI, 2013). Com base nos resultados da pesquisa, pode-se afirmar que a retextualização é um processo que faz parte do cotidiano envolvendo a comunicação (oral ou escrita) em diferentes esferas sociais, em especial, a produção textual em sala de aula. Ademais, as intervenções docentes durante o processo de produção escrita devem ser articuladas com a reescrita de textos do gênero alvo da produção e esta deve assumir lugar de destaque nesse processo, favorecendo a interlocução, a reflexão coletiva, a aprendizagem dos parceiros em sala de aula e a ampliação da capacidade comunicativa dos aprendizes em processo de formação.
\end{abstract}

Palavras-chave: Gêneros do discurso. Retextualização. Trabalho docente

\begin{abstract}
In this paper, the objective is to discuss processes of retextualization, textual correction and teaching work involving the written production in school. The approach to the object of investigation starts from a perspective of interpretative analysis, being the research of bibliographic nature, based on studies of the genres of discourse in the Bakhtinian perspective (BAKHTIN, 2006), with emphasis on retextualization (DELL'ISOLA, 2007; MARCUSCHI, 2007; SILVA; ANDRADE; MOREIRA, 2015), correction typologies and teaching work involving textual production (SERAFINI, 1995; FIAD, 2009; GONÇALVES, 2009; RUIZ, 2010; GASPAROTTO; MENEGASSI, 2013). Based on the results of the research, it can be stated that retextualization is a process that is part of everyday life involving communication (oral or written) in different social spheres, especially textual production in the classroom. In addition, the teaching interventions during the written production process must be articulated with the rewriting of texts of the target genre of the production and this must assume a prominent place in this process, favoring the interlocution, collective reflection, the learning of partners in the classroom and the expansion of the communicative capacity of apprentices in the training process.
\end{abstract}

Keywords: Speech genres. Retextualization. Teaching work

* Doutor em Letras e professor da Universidade Federal do Tocantins. E-mail: cicolinas@yahoo.com.br 


\section{INTRODUÇÃO}

Este artigo integra uma pesquisa ${ }^{1}$ mais ampla desenvolvida para consecução da nossa dissertação de mestrado vinculada ao Programa de Pós-Graduação em Letras: Ensino de Língua e Literatura (PPGL) da Universidade Federal do Tocantins (UFT), sendo objeto de estudo o processo de retextualização na construção do gênero Caderno da Realidade (CR), um instrumento didático-pedagógico adotado na Escola Família Agrícola Zé de Deus (EFAZD), situada em um município do interior do Estado do Tocantins (SILVA, 2011).

Ao mesmo tempo, é um artigo que pode ser tomado como um desdobramento de nossos estudos desenvolvidos em colaboração com outros autores (SILVA, 2011; SILVA; ANDRADE, 2014; SILVA; ANDRADE; MOREIRA, 2015), porém, agora com objetivo específico de discutir processos de retextualização, correção textual e o trabalho do professor envolvendo a produção escrita de gêneros do discurso na escola. A pesquisa é de natureza bibliográfica, de abordagem qualitativo-interpretativista (FLICK, 2009). Para fins de exemplificação, ilustramos um exemplar de um gênero produzido no contexto da sala a partir de uma proposta de retextualização.

Neste trabalho, estamos compreendendo os gêneros do discurso como "[...] 'tipos relativamente estáveis de' enunciados" (BAKHTIN, 2006, p. 262). Na perspectiva dialógica da linguagem, os gêneros são 'relativamente estáveis' porque “[...] atendem as especificidades de comunicação de cada esfera quando se faz uso da linguagem" e é por meio "[...] dos processos sociais ou de interação verbal que os gêneros são originados" (SILVA; ANDRADE; MOREIRA, 2015, p. 360). Portanto, os gêneros do discurso apresentam três elementos básicos: conteúdo temático, estilo linguístico e construção composicional. Logo, são elementos pertencentes a atividades de linguagem, os quais medeiam as práticas sociais. Nesse sentido, os gêneros do discurso, “[...] materializados em textos, configuram a realidade das ações e das atividades de linguagem dos atores sociais, sendo frutos das interações humanos em determinado contexto social" (SILVA; GONÇALVES, 2019, p. 3657).

O estudo dos gêneros do discurso na perspectiva de Bakhtin (2006), além da estrutura, circulação na sociedade, entre outros elementos, também deve abordar aspectos do modo de produção. Levando em consideração que esta pesquisa está focada em gêneros (escritos) que se materializam em textos e que, por sua vez, fazem parte do cotidiano da sala de aula e também de outras esferas sociais da comunicação humana, torna-se fundamental discutirmos a dinâmica de produção textual atrelada a processos de retextualização.

Portanto, este trabalho está organizado em duas partes principais. Primeiramente, discutimos/situamos processos de retextualização de textos orais e escritos, considerando os diferentes contextos de ensino e manifestação da linguagem. Por último, focalizamos as tipologias de correção textual e o trabalho docente com a (re)escrita na sala de aula.

\section{O PROCESSO DE RETEXTUALIZAÇÃO}

O termo retextualização foi empregado pela primeira vez no Brasil em 1993, por Neusa Gonçalves Travaglia, em sua tese de doutoramento intitulada A traducão numa perspectiva textual. Nessa obra, a autora concebe a tradução de uma língua para outra enquanto processo de retextualização (SILVA, 2011). A partir desse trabalho, Marcuschi (2007) estabelece em

\footnotetext{
${ }^{1}$ Esta pesquisa contribui para as atividades científicas do Grupo de Estudos e Pesquisas em Educação do Campo - GEPEC/CNPq.
} 
suas pesquisas outras possibilidades de retextualização envolvendo deferentes gêneros do discurso (orais ou escritos).

A "passagem" ou "transformação" de um texto falado em texto escrito ou vice-versa, em nosso cotidiano, é uma atividade bastante recorrente. Segundo Marcuschi (2007), esse processo é denominado de retextualização. Na sequência, apresentamos na Figura 1 os quatro tipos mais comuns ou possibilidades de retextualização quando operamos com os gêneros do discurso:

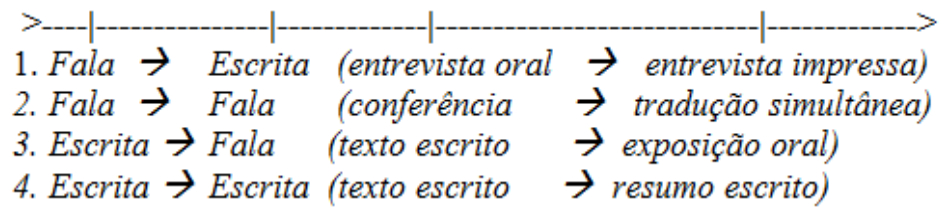

Figura 1 - Possibilidades de Retextualização

Fonte: Adaptado de Marcuschi (2007, p. 48) por Silva (2011, p. 71).

Marcuschi (2007) lembra que a retextualização não pode ser compreendida como um processo mecânico, já que em nossas atividades comunicativas é frequente depararmos com reformulações dos mesmos textos envolvendo variação de registros, gêneros do discurso, níveis linguísticos e estilos. Cabe salientar também que "toda vez que repetimos ou relatamos o que alguém disse, até mesmo quando produzimos as supostas citações ipsis verbis, estamos transformando, reformulando, recriando e modificando uma fala em outra" (MARCUSCHI, 2007, p. 48). Todas essas atividades são retextualizações. Portanto, são atividades rotineiras que se realizam de diversas maneiras em diferentes esferas de nossa sociedade, o que significa dizer que não ocorrem apenas na sala de aula. Por exemplo, quando uma secretária recebe uma chamada telefônica e produz um recado escrito; um escrivão registra por escrito a tomada de depoimento durante uma audiência; um relator participa de uma reunião e lavra a ata; um jornalista entrevista pessoas e produz uma reportagem, podemos dizer que em todos esses eventos linguísticos um texto oral foi retextualizado em um texto escrito. Esses mesmos gêneros podem ser transformados em outros: o recado escrito pode ser transformado em um aviso escrito; as decisões tomadas na reunião e registradas na ata podem ser transformadas em um manifesto escrito do grupo; a reportagem escrita pode ser transformada em sintese escrita das matérias de destaque da semana, caracterizando a retextualização de texto escrito para texto escrito. Segundo cada R do esquema ilustrado na Figura 2, há uma operação diferente de retextualização:

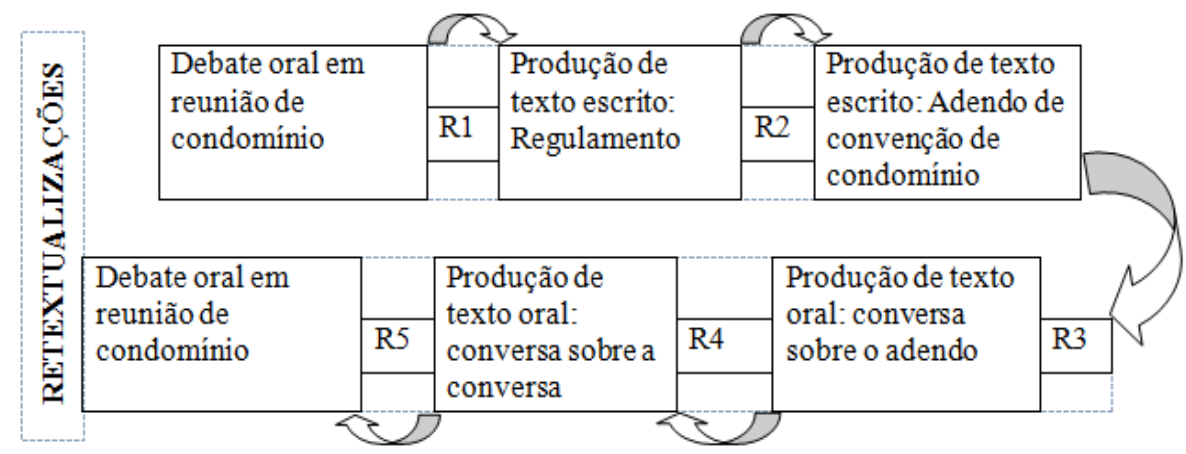

Figura 2 - Retextualizações

Fonte: Adaptado de Dell'Isola (2007, p. 37) por Silva (2011, p. 72). 
O R1 traz a passagem da fala para escrita; o R2 exemplifica a transformação da escrita para escrita; o R3, passagem da escrita para a fala; em R4 e R5 acontece a transformação da fala para a fala. Como podemos observar, todas as atividades de retextualização apresentadas no esquema são bastante comuns em nosso dia a dia. Na concepção de Dell'Isola (2007, p. 10), a retextualização é o "processo de transformação de uma modalidade textual em outra, ou seja, trata-se de uma refacção e reescrita de um texto para outro, processo que envolve operações que evidenciam o funcionamento social da linguagem". Depreendemos que a refacção e a reescrita são atividades fundamentais nas operações de retextualização de diferentes gêneros. Em se tratando de gêneros produzidos pelo aluno, com o objetivo de torná-los (mais) adequados à situação de interação prevista para seu funcionamento, entendemos que essas atividades podem envolver apenas o aluno (refacção) ou a participação do professor (reescrita). Em síntese, a retextualização é um processo que requer a passagem de "um texto para outro", de "um gênero para outro", em "modalidades" diferentes, tal como estabelece Marcuschi (2007), mas que na sala de aula demanda etapas bem definidas que contemplam escrita, revisão e reescrita ao longo do processo de produção.

$\mathrm{Na}$ tentativa de estabelecer diferenças entre refacção e reescrita, já que fazem parte das operações de retextualização, buscamos outros estudos que tratam do assunto. Para Fiad (2009, p. 9), reescrita "refere-se principalmente ao conjunto de modificações escriturais pelas quais diversos estados do texto constituem as sequências recuperáveis visando um texto terminal". Ou seja, envolve aspectos enunciativos gerais e processos individuais, o que ajuda a caracterizar os alunos em seus diferentes percursos formativos, em especial sobre a aprendizagem da escrita. É uma atividade que envolve a participação do professor ou de outra pessoa. Tal como advoga Gonçalves (2009, p. 21), “a reescrita é parte integrante da atividade escrita". Trata-se dos aspectos relacionados às mudanças de um texto no seu interior, isto é, uma escrita para outra, reescrevendo o mesmo texto. Alinhados a essa mesma perspectiva, Gasparotto e Menegassi (2013, p. 29) defendem que "a revisão e a reescrita textual, etapas fundamentais para a construção textual, revelam o olhar analítico sobre o texto construído, a fim de adequar sua estrutura e conteúdo à maior compreensão do leitor, mantendo o objetivo comunicativo do enunciador". Portanto, nossa perspectiva sobre reescrita textual dialoga com as considerações desses autores.

Já a refacção, de acordo com o conceito delineado nos PCN (BRASIL, 2001 [1998], p. 77), não é “[...] mera higienização, mas profunda reestruturação do texto, já que entre a primeira versão e a definitiva uma série de atividades foi realizada". Segundo esses documentos oficiais, a refacção acontece no decorrer do processo de produção escrita do texto, quando se releem trechos para prosseguir a redação, se reformulam passagens etc. Entre uma e outra versão do texto são realizadas diversas atividades. O papel do professor nesse processo é apenas mediar e organizar as atividades juntamente com os alunos, de modo que estes possam desenvolver capacidades necessárias à autocorreção. Concomitantemente, orienta-se que o docente elenque atividades e realize um estudo das questões linguísticas e discursivas manifestadas nos textos (BRASIL, 2001 [1998]).

Em relação a essa concepção de refacção ilustrada dos PCN, notamos que ela não apresenta distinção entre refacção e reescrita. Apesar de não ser evidenciado o uso do termo reescrita nos documentos oficiais, eles trazem um conceito de refacção que envolve a participação docente no processo, semelhante ao conceito de reescrita concebido por Fiad (2009). 
De acordo com os trabalhos de Abaurre, Fiad e Mayrink-Sabinson (1997, p. 8), refacção refere-se "às operações epilinguísticas dos sujeitos da escrita, que refazem seus textos com relação a aspectos geralmente não apontados por seus professores". Entendemos, segundo as autoras, que as operações de refacção envolvem um processo de maior autonomia para o autor do texto, sendo que ele altera seu próprio texto, sem interferências do professor; diferentemente da reescrita, na qual o trabalho tem a participação direta do professor ou de outra pessoa.

Os processos de retextualização permitem transpor o conteúdo de um texto para outro, exigindo a mudança de gênero (oral ou escrito e vice-versa). Isso requer, antes de qualquer coisa, compreensão sobre o que se disse e o que se quis dizer, o que se escreveu e os resultados manifestados pelo novo gênero que se produziu (SILVA, 2011; SILVA; ANDRADE; MOREIRA, 2015). "Portanto, antes de qualquer atividade de transformação textual, ocorre uma atividade cognitiva denominada compreensão"2 (MARCUSCHI, 2007, p. 47). Logo, essa atividade cognitiva pode refletir nos propósitos comunicativos do gênero no contexto social, levando-o a ser avaliado como bem ou malsucedido. Assim como na produção de qualquer texto a partir de determinado tema, na retextualização devem ser consideradas as condições de produção, de circulação e de recepção dos textos. São princípios inerentes a qualquer evento comunicativo (SILVA, 2011).

Em seus estudos, Marcuschi (2007, p. 54) propõe quatro variáveis que agem na retextualização. A primeira, denominada de propósito ou objetivo da transformação, refere-se à finalidade da transformação, já que qualquer retextualização apresenta objetivos a serem alcançados. Dependendo de quem vai ler ou do contexto em que o texto irá circular, o nível de linguagem pode ser diferente (formal/não formal). A segunda variável delineada pelo autor diz respeito à relação entre o produtor do texto original e o transformado. Como sabemos, um texto pode ser retextualizado pela mesma pessoa que produziu o original ou por um terceiro. A retextualização feita por quem é o próprio autor parece apresentar mudanças mais acentuadas. Já a terceira variável diz respeito à relação de tipologia entre o gênero original e o gênero retextualizado. A mudança na passagem de um gênero para outro resulta modificações significativas, como transformar um conto de fadas em um poema. A última ou quarta variável trata dos processos de formulação. Esta categoria envolve as estratégias do produto textual vinculado a cada modalidade. Essas variáveis estão ilustradas no Quadro 1:

\begin{tabular}{|c|l|}
\hline \multicolumn{2}{|c|}{ Descrição das Variáveis } \\
\hline I & O propósito ou objetivo da retextualização. \\
\hline II & A relação entre o produtor do texto original e o transformado. \\
\hline III & A relação tipológica entre o gênero textual original e o gênero da retextualização. \\
\hline IV & Os processos de formulação típicos de cada modalidade. \\
\hline
\end{tabular}

Quadro 1 - Variáveis intervenientes na Retextualização

Fonte: Adaptado de Marcuschi (2007, p. 54) por Silva (2011, p. 75).

Com base nessas variáveis, Dell'Isola (2007, p. 43) lembra que “a compreensão é atividade onipresente" no processo de retextualização. A leitura e a compreensão do texto original devem considerar, no mínimo, a primeira e as duas últimas variáveis apresentadas.

\footnotetext{
${ }^{2}$ Para retextualizar um gênero, antes de qualquer procedimento, precisamos entender o que o gênero original nos diz ou o que seu autor quis dizer. Se não fizermos isso, nosso texto (retextualizado) poderá apresentar problemas, especialmente no que se refere à coerência (SILVA, 2011).
} 
Nas práticas pedagógicas, os gêneros do discurso com que nossos alunos têm mais contato no cotidiano podem ser utilizados nos processos de retextualização, o que certamente contribui para que se tornem proficientes na leitura e na escrita de textos. Silva (2011) lembra que o Caderno da Realidade (CR), produzido no contexto de ensino da Pedagogia da Alternância, dada a sua natureza textual e discursiva, pode ser bem explorado nesse tipo de atividade com os alunos.

Silva (2011) também chama a atenção do leitor para o fato de que as operações de retextualização contempladas em seu estudo sobre o CR são apenas aquelas que envolvem a transformação de um texto escrito para outro texto escrito, de um gênero para outro gênero. Ou seja, são retextualizações caracterizadas pelas transformações de gêneros escritos, a transposição do conteúdo de um texto para outro, bem como a mudança de gênero (SILVA, 2011).

A título de exemplo de retextualização, tomamos como base uma produção que desenvolvemos na EFAZD com o poema O bicho, de Manuel Bandeira:

\section{O Bicho}

Vi ontem um bicho

$\mathrm{Na}$ imundície do pátio

Catando comida entre os detritos.

Quando achava alguma coisa,

Não examinava nem cheirava:

Engolia com voracidade.

O bicho não era um cão,

Não era um gato,

Não era um rato.

O bicho, meu Deus, era um homem.

Fonte: Bandeira (1947).

Considerando (1) a relevância da temática social que esse poema aborda e (2) a proposta de produção textual na disciplina Língua Portuguesa, em uma turma do $2^{\circ}$ ano do Ensino Médio da EFAZD, lançamos o desafio aos alunos: produzir um gênero escrito (conto) com base em um gênero escrito, neste caso, o poema O bicho, de Manuel Bandeira. A seguir, apresentamos a última versão (inédita) de uma das produções depois de ter passado por diferentes etapas envolvendo: escrita da versão inicial, revisão e reescrita. 


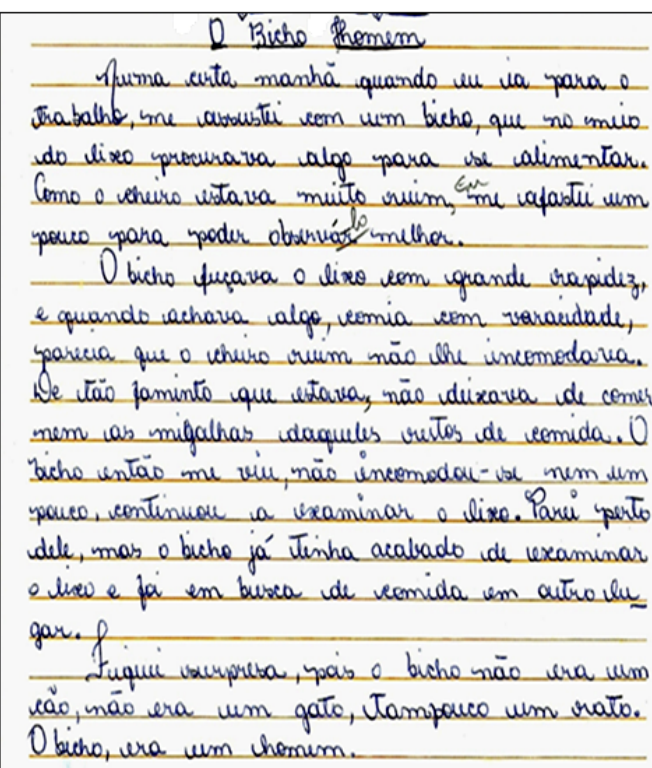

\section{O Bicho Homem}

Numa certa manhã, quando eu ia para o trabalho, assustei-me com um bicho, que no meio do monturo procurava algo para se alimentar. Como o cheiro estava muito ruim, eu me afastei um pouco a fim de poder observá-lo melhor.

O bicho fuçava o lixo com grande rapidez, e quando achava algo, comia com voracidade. Parecia que o cheiro ruim não lhe incomodava. De tão faminto que estava, ele não deixava de comer nem as migalhas daqueles restos de comida em putrefação. O bicho então me viu, entretanto não se incomodou nem um pouco, continuou a examinar a lixo. Aproximei-me e parei perto dele, mas o coitado já havia acabado de examinar o lixo e saiu em busca de comida, certamente, em outro lugar.

Fiquei surpresa, pois o bicho não era um cão, não era um gato, tampouco um rato. $\mathrm{O}$ bicho, gente, era um homem.

(Aluna: Lara, $2^{\circ}$ ano EFAZD/2009).

Texto 1 - O bicho homem

Fonte: Pesquisa do autor (2019).

Esse exemplar (Texto 1) do gênero conto foi produzido por Lara ${ }^{3}$, uma das alunas do $2^{\circ}$ ano do Ensino Médio. Observa-se que, com base na temática de um gênero escrito (poema), a estudante foi capaz que produzir um novo gênero escrito (conto), inclusive, ampliando a discussão do tema: a miséria humana. Portanto, atividades como essa podem ser desenvolvidas em sala de maneira bem-sucedida. Paralelo à produção, cabe ao professor assumir nas atividades a revisão e reescrita, conforme discutiremos na próxima seção.

Em síntese, na esfera escolar ou em qualquer outra, a retextualização de um gênero (oral ou escrito) exige basicamente: a) compreensão sobre o gênero original e o que está sendo retextualizado; b) consideração a respeito dos diversos aspectos dos gêneros, como condições de produção, função social e propriedades; c) manutenção de traços que identifiquem o gênero retextualizado (SILVA; ANDRADE; MOREIRA, 2015). Podemos afirmar, então, que é um processo que ultrapassa as questões meramente linguísticas, pois requer a adequação do texto à determinada situação comunicativa, ao estilo e ao gênero discursivo em uma atividade interativa envolvendo professor e aluno. Como veremos na sequência, as intervenções docentes fazem parte desse processo.

\section{PRODUÇÃO ESCRITA, CORREÇÃO TEXTUAL E INTERVENÇÃO DOCENTE}

A produção escrita de gêneros do discurso, como atividade interativa, envolve intervenções ou encaminhamentos dos docentes em forma de correção. ${ }^{4}$ Evidentemente, tais intervenções estão relacionadas diretamente ao ensino ou uso de língua materna.

\footnotetext{
${ }^{3}$ Por questões éticas, adotamos pseudônimo para assegurar o anonimato da autora do texto.

${ }^{4}$ A correção (SERAFINI, 1995) refere-se ao conjunto de intervenções que o docente executa para apontar defeitos e erros, certo tipo de diagnóstico. Assim, geralmente a avaliação é subsequente à fase
} 
A partir de seus estudos sobre as revisões textuais (correção de professores), Serafini (1995) explicita três tipos ou categorias muito comuns de correções adotados por professores: a correção indicativa, a correção resolutiva e a correção classificatória. A autora afirma que as correções resolutiva e indicativa são as mais recorrentes entre os professores. $\mathrm{Na}$ correção resolutiva as intervenções do professor limitam-se a focalizar as "intenções" dos alunos e em seguida reescrever os trechos que para ele parecem confusos. Segundo Santos e Bezerra (2010, p. 159), "o problema maior atribuído a esse tipo de correção é que, no momento em que o professor refaz o que estava confuso na redação do aluno, ele tira do sujeito que produz a oportunidade de refletir sobre sua própria redação.” Dessa maneira, o autor do texto não consegue perceber ou identificar seus próprios "equívocos".

Já na correção indicativa, geralmente, as intervenções docentes recaem sobre inadequações estruturais, lexicais e ortográficas. Ou seja, é um trabalho que se limita à identificação dos chamados "erros", sem esclarecer ao aluno que tipo de "erro" cometeu e como saná-los. E são "erros" que, geralmente, fazem parte do emprego da norma culta da língua materna pelo aluno. Nesta categoria de correção, a escrita tem um fim em si mesmo, "podando" nela qualquer tipo de possibilidade de reescrita ou de reflexão (RUIZ, 2010).

No que diz respeito às características da correção classificatória, podemos afirmar que esta se diferencia das correções resolutiva e indicativa em função do trabalho desempenhado pelo professor ocorrer de forma mais objetiva, uma vez que torna o aluno ciente dos encaminhamentos que precisa seguir em sua redação para aprimorá-la. Por sua vez, cabe ao docente sugerir ao aluno as devidas modificações. Para tanto, é fundamental que o discente compreenda as sugestões, pois deve procurar reescrever seu texto individualmente. Como defendem Santos e Bezerra (2010, p. 159), um dos fatores que nos permite afirmar que a correção classificatória apresenta pontos positivos, ocorre pelo fato de que ela permite indicar "onde" e que tipo de "erro" o aluno-autor praticou, de modo que o professor pode sugerir as modificações de maneira clara.

Mas a partir dessas três tendências de correções (SERAFINI, 1995), em seus estudos sobre redações de alunos de diferentes níveis escolares, com faixa etária entre 9 e 23 anos, Ruiz (2010) identificou outra categoria de correção, cunhada pela autora de correção textualinterativa. Trata-se de uma tipologia de correção que transcende a correção realizada pelo professor na modalidade classificatória. Nesta, geralmente os comentários do docente são realizados em forma de "pequenos bilhetes", denominados também por Ruiz (2010) como pós-texto, já que seguem o texto do aluno. Neste tipo de correção, o professor expõe maiores informações sobre a escrita dos alunos no espaço em branco deixado por eles. Isso torna desnecessário encaminhar comentários nas margens do texto original. Evidentemente, os "comentários deixados pelo professor aos alunos não se limitam apenas aos 'erros' encontrados em suas redações, mas referem-se também a boa progressão que o texto teve" (SANTOS; BEZERRA, 2010, p. 159).

Outro aspecto positivo identificado nesta categoria de correção refere-se ao estabelecimento de "um contato mais próximo do professor com as escritas dos alunos". Por meio dos "bilhetes" que o professor encaminha nos textos, há uma possibilidade maior de os alunos compreenderem o que precisa ser melhorado em seus textos e os pontos positivos também, o que requer, por usa vez, um incentivo maior para que refaçam seus textos com

da correção. A avaliação ocorre com base em anotações presentes no texto, feitas a partir das correções. 
mais cautela, atentando para as sugestões advindas do professor (SANTOS; BEZERRA, 2010).

Além dessas quatro categorias, Gonçalves (2009) estabelece uma outra forma de intervenção na produção textual inicial do aluno, denominada de intervenção interativa. A proposta desse autor (por meio da intervenção interativa) difere basicamente da correção textualinterativa (RUIZ, 2010) porque esta trata dos bilhetes interativos, geralmente no pós-texto. As intervenções caracterizadas pela correção interativa estão associadas à intervenção por meio da utilização de lista de controle/constatações, denominada na literatura suíça de "grille de contrôle" (SCHNEUWLY; DOLZ, 2004). Na verdade, a lista de controle/constatações refere-se a uma série de itens que caracterizam os gêneros do discurso em análise ou às categorias que serão utilizadas após a aplicação da Sequência Didática (SD) ${ }^{5}$. Como enfatiza Gonçalves (2009, p. 19), para que a correção interativa aconteça, o trabalho deve inicialmente utilizar as SD e, na sequência, a "lista de controle/constatações" como instrumento regulador da aprendizagem. Isso também vai depender da prática da reescrita. $\mathrm{O}$ autor lembra ainda que "a reescrita vai, obviamente, exigir do professor uma concepção dialógica da linguagem, que é o seu verdadeiro papel; isto é, a reescrita vai possibilitar ao aluno ajustar o que se tem a dizer à forma de dizer de um determinado gênero" (p. 19). Ela permite realizar intervenções não contempladas pelas outras quatro tipologias de correções propostas por Serafini (1995) e Ruiz (2010).

Ademais, Menegassi (2013), ao investigar a revisão textual na formação inicial, enfatiza, entre outras coisas, a escrita como trabalho, uma ação prioritária da aprendizagem e do ensino, a qual se desenvolve por meio de diferentes etapas indispensáveis para o aprimoramento da escrita, como: planejamento, execução, revisão e reescrita. Por sua vez, o professor assume o papel de interlocutor do aluno/aprendiz durante todo o processo de produção textual. O autor também chama a atenção para a importância da adoção da revisão textual-interativa, pois nesta modalidade de revisão o professor tem a oportunidade de apresentar no corpo do texto do aluno comentários sobre eventuais inadequações na escrita em forma de bilhetes. Mais uma vez, ressalta-se que neste tipo de revisão efetiva-se uma relação de troca, ou seja, acontece um diálogo entre o autor (aluno) do texto e o revisor (professor), o que tem o potencial de gerar mudanças e se chegar a um texto final em um nível muito melhor do que a versão inicial.

Como vimos anteriormente, uma das atividades importantes no processo de retextualização é a reescrita. Esta, por sua vez, para ser colocada em prática depende da participação docente por meio de encaminhamentos e intervenções (revisões) durante o processo de produção escrita de qualquer gênero que se proponha a produzir.

\section{CONCLUSÃO}

Considerando que o foco da investigação relatada neste artigo é a retextualização, as tipologias de correção textual e o trabalho do professor implementado na escola para mediar a produção escrita dos alunos, com base nos resultados da pesquisa pode-se afirmar que:

\footnotetext{
${ }^{5}$ Constitui, basicamente, um conjunto de atividades escolares organizadas (SCHNEUWLY; DOLZ, 2004, p. 82), de forma sistemática, abordando um gênero oral ou escrito. Seu objetivo é ajudar o aluno a dominar melhor um gênero textual/discursivo, de modo que possa falar ou escrever conforme a situação de comunicação. Geralmente, uma SD é estruturada com as seguintes etapas: apresentação da situação; produção inicial; módulo 1; módulo 2; módulo n; e produção final.
} 
1) a retextualização é um processo que faz parte do cotidiano envolvendo a comunicação (oral e escrita) em diferentes esferas sociais, em especial, a produção textual em sala de aula;

2) no que diz respeito às intervenções (revisões) docentes durante o processo de produção escrita, estas devem ser articuladas com a reescrita de textos do gênero alvo da produção e esta deve assumir lugar de destaque nesse processo, favorecendo a interlocução, a reflexão coletiva, a aprendizagem dos parceiros em sala de aula e a ampliação da capacidade comunicativa dos aprendizes (alunos) em processo de formação.

Portanto, a literatura que enfoca o tema reforça que a produção de qualquer gênero do discurso faz parte e é de fundamental importância para o letramento e o ensino da língua, a exemplo da produção do gênero Caderno da Realidade (CR) analisado em nossas pesquisas (SILVA, 2011, 2018; SILVA; ANDRADE, 2014; SILVA; ANDRADE; MOREIRA, 2015). Não temos dúvidas de que o $\mathrm{CR}$ pode ser tomado como um instrumento de grande importância para o ensino de Língua Materna nos Centros Familiares de Formação por Alternância (CEFFA) ${ }^{6}$, especialmente da modalidade escrita.

Mas para que isso ocorra nos CEFFA ou em qualquer outro tipo de unidade de ensino, a produção escrita exige que sejam estabelecidos parâmetros metodológicos apropriados pelo professor. "Isso permite que as condições de produção e recepção dos textos sejam outras, gerando bons textos (retextualizados ou não)" (SILVA; ANDRADE; MOREIRA, 2015, p. 369). Nessa perspectiva, o estudante poderá melhorar seu desempenho e alcançar sucesso nas produções escritas, ampliando sobremaneira sua capacidade de escrever diferentes gêneros do discurso, como evidencia o Texto 1. Trata-se, portanto, de um desafio enfrentado não só na formação na educação básica mas também no ensino superior.

\section{REFERÊNCIAS}

ABAURRE, Maria Bernadete Marques; FIAD, Raquel Salek; MAYRINK-SABINSON, Maria Laura Trindade. Cenas de aquisição da escrita: o sujeito e o trabalho com o texto. Campinas: Mercado de Letras: Associação de Leitura do Brasil - ALB, 1997.

BAKHTIN, Mikhail. Os gêneros do discurso. In: BAKHTIN, Mikhail. Estética da criação verbal. 4. ed. São Paulo: Martins Fontes, 2006. p. 261-335.

BANDEIRA, Manuel. O bicho. 1947. Disponível em: https://www.escritas.org/pt/t/4828/o-bicho Acesso em: 09 out. 2019.

BRASIL. Secretaria de Educação Fundamental. Parâmetros Curriculares Nacionais: terceiro e quarto ciclos do Ensino Fundamental - Língua Portuguesa. Brasília: $\mathrm{MEC} / \mathrm{SEF}, 2001$ [1998].

DELL'ISOLA, Regina Lucia Peret. Retextualização de gêneros escritos. Rio de Janeiro: Lucerna, 2007.

\footnotetext{
${ }^{6}$ No Brasil, as unidades de ensino que adotam o sistema pedagógico da Pedagogia da Alternância recebem essa denominação. A título de exemplificação, os CEFFA mais conhecidos são as Escolas Famílias Agricolas (EFA) e as Casas Familiares Rurais (CFR). Seus objetivos são comuns, que é oferecer formação às crianças e aos jovens camponeses (SILVA, 2011).
} 
FIAD, Raquel Salek. Episódios de reescrita em textos infantis. Estudos Linguísticos, São Paulo, v. 38, n. 2, p. 9-18, 2009.

FIAD, Raquel Salek; MAYRINK-SABINSON, Maria Laura Trindade. A escrita como trabalho. In: MARTINS, Maria Helena (Org.). Questões de linguagem. 6. ed. São Paulo: Contexto, 2001. p. 54-63.

FLICK, Uwe. Introdução à pesquisa qualitativa. 3. ed. Porto Alegre: Artmed, 2009.

GASPAROTTO, Denise Moreira; MENEGASSI, Renilson José. A mediação do professor na revisão e reescrita de textos de aluno de Ensino Médio. Calidoscópio, São Leopoldo, v. 11, n. 1, p. 29-43, jan./abr. 2013.

GONÇALVES, Adair Vieira. As listas de controle/constatações como ferramentas para a reescrita de gêneros. In: GONÇALVES, Adair Vieira; BAZARIM, Milene. (Orgs.). Interação, gêneros e letramento: a (re)escrita em foco. São Carlos: Claraluz, 2009. p. 17-34.

MARCUSCHI, Luiz Antônio. Da fala para escrita: atividades de retextualização. 8. ed. São Paulo: Cortez, 2007.

MENEGASSI, Renilson José. A revisão de textos na formação inicial. In: GONÇALVES, Adair Vieira; BAZARIM, Milene. Interação, gêneros e letramento: a (re)escrita em foco. 2 ed. Campinas: Pontes Editores, 2013. p. 105-131.

RUIZ, Eliana Donaio. Como corrigir redações na escola. São Paulo: Contexto, 2010.

SANTOS, Joelma da Silva; Bezerra, Maria Auxiliadora. Produções textuais de alunos de letras e recepção do professor. Cadernos de Letras da UFF, Rio de Janeiro, n. 40, p. 153-175, 2010.

SCHNEUWLY, Bernard; DOLZ, Joaquim. Os gêneros escolares - das práticas de linguagem aos objetivos de ensino. In: SCHNEUWLY, Bernard; DOLZ, Joaquim. Gêneros orais e escritos na escola. Campinas: Mercado de Letras, 2004. p. 61-78.

SERAFINI, Maria Teresa. Como escrever textos. Rio de Janeiro: Globo, 1995.

SILVA, Cícero da. Pedagogia da Alternância: práticas de letramentos em uma Escola Família Agrícola brasileira. 2018. 232f. Tese (Doutorado em Letras: Ensino de Língua e Literatura) - Universidade Federal do Tocantins, Araguaína, 2018.

SILVA, Cícero da. Pedagogia da Alternância: um estudo do gênero Caderno da Realidade com foco na retextualização. 2011. 149f. Dissertação (Mestrado em Letras: Ensino de Língua e Literatura) - Universidade Federal do Tocantins, Araguaína, 2011.

SILVA, Cícero da; GONÇALVES, Adair Vieira. O gênero Caderno de acompanhamento na Pedagogia da Alternância: espaço de diálogo entre família e escola. Fórum Linguístico, Florianópolis, v. 16, n. 2, p. 3655-3668, 2019. https://doi.org/10.5007/1984-8412.2019v16n2p3655 
SILVA, Cícero da; ANDRADE, Karylleila dos Santos; MOREIRA, Flavio. A retextualização no gênero Caderno da Realidade na Pedagogia da Alternância. Acta Scientiarum. Language and Culture, Maringá, v. 37, n. 4, p. 359-369, out./dez., 2015. http://dx.doi.org/10.4025/actascilangcult.v37i4.25050

SILVA, Cícero da; ANDRADE, Karylleila dos Santos. Produção escrita em uma EFA tocantinense e o trabalho docente. In: SILVA, Luiza Helena Oliveira da; MELO, Márcio Araújo de; OLIVEIRA, Luiz Roberto Peel Furtado de (Org.). Ensino de Lingua e Literatura: pesquisas na Pós-graduação. Palmas: EdUFT, 2014. v. 01, p. 189-206.

Recebido em: 09/10/2019

Aprovado em: 07/12/2019

Publicado em: 19/12/2019 